\title{
Modelagem do processo de atendimento em salas de recursos para alunos com necessidades educacionais especiais
}

\author{
Caroline Mundel $^{1}$, Francisco Dutra dos Santos Jr. ${ }^{1}$, Leandro Krug Wives ${ }^{1}$ \\ ${ }^{1}$ PPGIE - CINTED - UFRGS \\ CEP 90.040-060 - Porto Alegre - RS - Brasil \\ \{kkmundel, prof.chicosantosjr\}@gmail.com, leandro.wives@ufrgs.br
}

\begin{abstract}
In Brazil, there are incentivizing regulations for the implementation of multifunctional resource rooms in public schools to support the organization and provision of specialized educational services, contributing to the strengthening of the educational inclusion process, but there is no defined standard for care in these environments. This paper maps the activities developed in these rooms, focusing on Porto Alegre, organizing them into a process model that can serve as the basis for the entire network.
\end{abstract}

Resumo. No Brasil há regulamentação de incentivo à implantação de salas de recursos multifuncionais em escolas públicas com o objetivo de apoiar a organização e oferta do atendimento educacional especializado, contribuindo para o fortalecimento do processo de inclusão educacional, mas não há um padrão definido para atendimento nesses ambientes. O presente trabalho mapeia as atividades desenvolvidas nessas salas, focando em Porto Alegre, organizando-as em um modelo de processo que possa servir de base para toda a rede.

\section{Introdução}

Grande parte das escolas de ensino fundamental contempla salas dotadas de infraestrutura e materiais didáticos e pedagógicos para apoiar a organização e a oferta do Atendimento Educacional Especializado (AEE). Esse atendimento é prestado de forma complementar ou suplementar aos estudantes com deficiência, transtornos globais do desenvolvimento ou altas habilidades/superdotação, matriculados no ensino regular. Porto Alegre possui salas próprias para o AEE, as Salas de Integração e Recursos (SIR), desde 1995 [Santos-Júnior 2002]. Nelas, os atendimentos ocorrem no turno inverso, e os professores que lá atuam possuem formação específica em educação especial. Embora essas salas estejam amplamente difundidas no sistema educacional brasileiro, não hã um padrão de atendimento - cada rede de ensino organiza seu próprio modelo de desenvolvimento de atividades.

Este trabalho utiliza técnicas de Gerenciamento de Processos de Negócios a fim de levantar as atividades desenvolvidas (as-is) e elaborar um modelo do processo de atendimento nessas salas. O principal benefício de analisar o estado atual é o entendimento comum de como o trabalho é feito. Cabe salientar que a modelagem de processos permite uma visão ampla do fluxo de atividades executadas para alcançar um objetivo em uma instituição, garantindo resultados consistentes e oferecendo oportunidades de melhoria [Dumas et al. 2012]. Em seguida, avaliamos o redesenho do processo [ABPMP 2013] a 
fim de repensar ponta a ponta sobre o que o processo está realizando atualmente. O redesenho é baseado na ideia de que o estado atual deve ser desafiado e que o processo precisa ser melhorado [Dumas et al. 2012].

Para sua execução, contou-se com a experiência de um dos autores, que atuou no AEE das SIR do referido Município desde sua implantação. Cabe salientar que a modelagem será focada nesse contexto específico, no Ensino Fundamental, e pode não ser o caso em outras redes ou níveis educacionais. Como instrumento de levantamento, utilizamos a análise de documentos e a entrevista. Para a documentação, utilizamos o Business Process Model and Notation (BPMN) do Object Management Group, que fornece uma notação compreensível por todos os usuários de negócios. Além disso, realizou-se uma descrição textual do processo, a qual é resumida a seguir.

\section{O processo mapeado}

A Figura 1 ilustra o processo de maneira global. O processo inicia quando o professor da SIR recebe um parecer de encaminhamento de um aluno. Com isso o professor entrevista sua família, professores, observa-o em seu contexto escolar e realiza encontros individuais. Se necessário, solicita a avaliação de um profissional da saúde. Após, elabora um parecer definindo a necessidade ou não de atendimento na SIR. Caso positivo, elabora um plano de desenvolvimento individualizado (PDI), que contempla o perfil do aluno, define o que será desenvolvido durante o seu atendimento e a quantidade de encontros necessários. Também desenvolve planos de Adequação Curricular, que propõem como os professores de sala de aula regular podem abordar cada conteúdo, de acordo com as necessidades do aluno.

Depois, inicia-se um ciclo de atendimento na SIR, onde, a cada encontro, faz-se o registro de atendimento, que envolve a frequência ou um relatório com fotos, vídeos e comentários a respeito do trabalho realizado e avanços identificados. Se necessário, contata a família do aluno, profissionais de saúde que o atendem ou assessora os professores de sala regular. Também pode redefinir a forma de atendimento ou ajustar o PDI, a adequação curricular ou os serviços de apoio.

A cada trimestre, no conselho de classe, o professor da SIR relata o atendimento realizado e contribui com a avaliação do aluno. No fim do ano, elabora parecer ao SOE. O ciclo encerra quando o aluno conclui sua formação, quando não necessita de atividades junto à SIR ou se desliga da escola.

Quando o aluno conclui o Ensino Fundamental é elaborado um parecer de Terminalidades Específicas, onde ficam registradas as habilidades e conhecimentos adquiridos, conforme previsto no art. 59, inciso II, da Lei de Diretrizes e Bases 9394/96. Caso o aluno se desligue por outros motivos, o professor elabora um parecer específico considerando as condições do aluno.

O processo foi validado através de encontros com professores que atuam em SIRs do município. A cada encontro, o modelo era apresentado e explicado, passo-a-passo, aos professores, para que o validassem e propusessem ajustes, se necessário. Todas as sugestões foram atendidas e a versão final foi encaminhada para os envolvidos a validarem. Durante a validação final, também foi apresentado o modelo to-be sugerido.

Considerando que as tarefas precisam ser mantidas, o modelo to-be(Figura 1 apre- 
senta apenas atividades adicionais relacionadas ao uso de um aplicativo de acompanhamento, o qual está sendo desenvolvido. Nele, o professor poderá realizar os registros do aluno direto de seu smartphone, incluindo PDIs e adequações curriculares, dispostos em uma timeline para visualização temporal. Os registros poderão ser importados para elaboração de pareceres e para a Terminalidade Específica. Considerando que as atividades existentes permaneceram no novo modelo, foi possível apresentar as sugestões de melhoria do processo, pois elas não foram impactadas pelas alterações propostas pelo grupo. Elas foram recebidas com entusiasmo por eles.

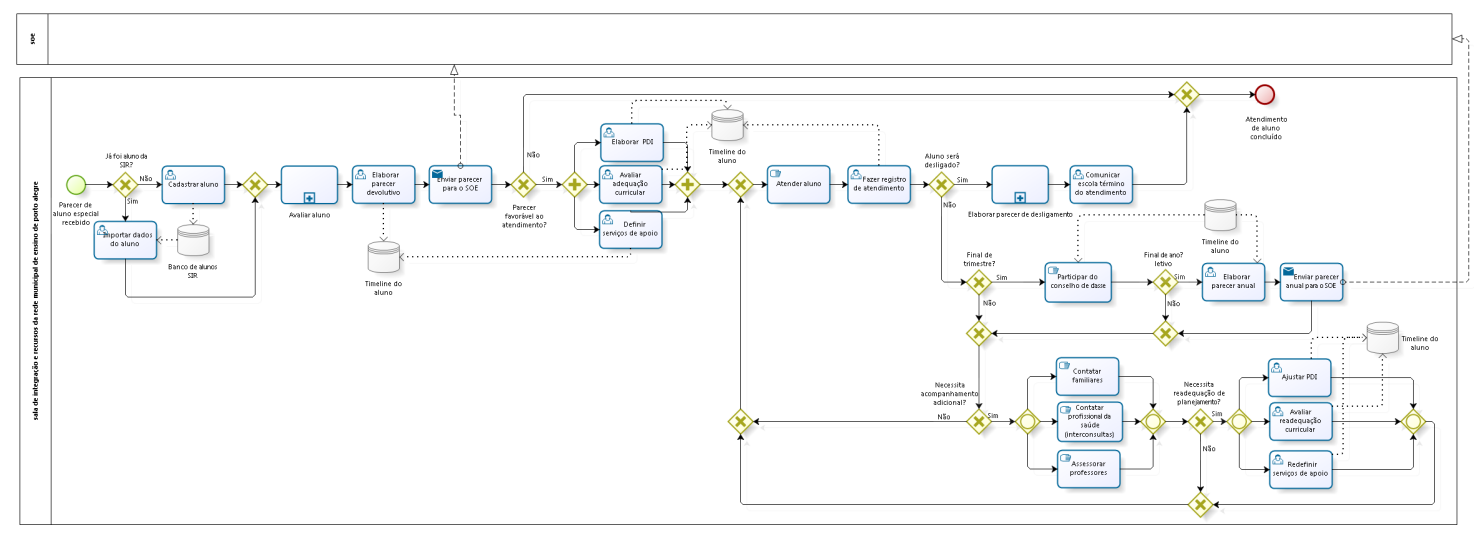

Figura 1. Modelo sugerido de processo (to-be)

\section{Considerações finais}

O presente trabalho mapeou as atividades realizadas durante o processo de atendimento de alunos com NEE nas SIR da Rede de Ensino de Porto Alegre. Utilizando técnicas de Gerenciamento de Processos de Negócios, foi elaborada a modelagem do processo como é executado atualmente ( $a s-i s$ ) e, a partir dele, foram sugeridas melhorias (to-be). Esperase que esses modelos sirvam de base para o entendimento do processo, tanto para os que estão desenvolvendo o sistema sugerido como para gestores e demais interessados em conhecer o processo atual. Os professores que tiveram acesso aos resultados demonstraram interesse na possibilidade de visualização do processo como um todo e ficaram entusiasmados com a possibilidade de um software para apoiá-los nas atividades desenvolvidas.

\section{Referências}

ABPMP (2013). BPM CBOK: Guia para o Gerenciamento de Processos de Negócio Corpo Comum de Conhecimento. Association of BPM Professionals, Brasil.

Dumas, M., La-Rosa, M., Mendling, J., and Reijers, H. A. (2012). Fundamentals of Business Process Management, 2nd ed. Springer.

Santos-Júnior, F. D. (2002). As Políticas de Educação Especial na Rede Municipal de Ensino de Porto Alegre: 1989 - 2000. Dissertação de Mestrado, Faculdade de Educação, UFRGS, Porto Alegre. 